\title{
Discussing the potential of using submersive water pumps powered by photovoltaic panels in agriculture and the alternative use for the supply of households in Romania.
}

\author{
Costăngioară ANA \\ Bucharest University of Economic Studies, Bucharest, Romania \\ ana_serbanescu@hotmail.com
}

\begin{abstract}
According to the current leadership of the EU Parliament, the use of renewable energy should not only represent a condition for emission reduction as an ecological demand, but also an opportunity to modernize the European economy and insure the sustainable development of the member countries. In this context, the aim of the current paper is to analyze the potential of using photovoltaic panels to power the water pumps utilized in both agriculture and supply of households in Romania and what the resulting impact would be from the ecological standpoint, as well as the economic and social one. The impact assessment follows the guideline proposed by the European House Ambrosetti latest publication regarding the socioeconomic impacts of the energy transition in Europe, but proposes a granular approach rather than a global one. The literature review of the existing publications presents an overview of the conclusions reached so far regarding water pumps powered by photovoltaic energy used for different purposes, such as the environmental and economic benefits of heat pump water heaters which are powered by photovoltaic energy or the performance comparison between photovoltaic heating systems and traditional ones. The current paper has the purpose of answering whether the utilization of photovoltaic powered water pumps in agriculture in Romania could bring economic and ecological benefits which would outweigh the costs and also, if this is the case, if there are also social benefits to be considered which would result in the use of this technology for households as well. The conclusions reach through this paper show the benefits of using the above mentioned technology for industrial purposes and its alternative potential for households. The contribution is to both the research field of renewable energy and its uses and to the policymakers to encourage investment in this direction.
\end{abstract}

Keywords: water pump, renewable energy, agriculture, impact, policymakers

\section{Introduction}

The process of energy transition represents a priority for the majority of the developed countries and has therefore become a goal for the European Union. It is defined as the process of replacing the use of fossil fuels with renewable energy and it is known that in order for it to be implemented, the cost reduction of the required technologies and the digitalization of the networks are essential conditions.

According to the current leadership of the Union, this should also become an opportunity to modernize the economy and encourage the development of the industrial sector, especially through innovation. In other words, the goal is not only to realize the energy transition, but to do so in a manner that would benefit the economy, the climate, the industry and the society of the Europeans. (The European House Ambrosetti, 2019).

The topic of this paper is referring to a strategic driver of the economy of Romania agriculture and it proposes a solution for one of the main issues: the lack of irrigation for a significant portion of the agricultural land. The hypothesis of the research is that by the use of photovoltaic powered water pumps for the irrigation of agricultural land during the transition to 
green energy is in line with the goals of the EU, according to which this transition must happen in a fair manner, in which both economic and social development are encouraged.

The methodology used in order to assess the impact of using photovoltaic powered water pumps is the one proposed by the European House Ambrosetti in their report on energy transition (evolution until 2030).

The significance of this subject is explained through the data provided by the National PICBE | 75 Statistics Institute regarding the importance of agriculture for the economic performance of Romania, as well as by the stringent goals set by the European Union in order to reduce the emissions and promote clean air policies which have the year 2030 set as deadline.

\section{Literature review}

In their paper "Performance comparison of photovoltaic/thermal solar water heating systems with direct-coupled photovoltaic pump, traditional pump and natural circulation" Huide Fu et al. (2019) have compared a photovoltaic/thermal system with direct-coupled photovoltaic pump with one with a traditional direct-coupled pump and with a natural circulation one. According to their results, photovoltaic/thermal system with photovoltaic pump had the best thermal performance among the three and the net energy obtained thereby was higher compared to the other two. The study approaches the subject from the technical perspective, by conducting a day-long experiment and comparing the heating systems with the different circulation methods.

According to A.A. Gohneim in his work "Design optimization of photovoltaic powered water pumping systems" the importance of using photovoltaics as the power source is underlined especially for pumping water, as the sun is a renewable energy source which is clean and produces neither green house effect gases nor hazardous wastes through its utilization. The use of photovoltaic power is also justified by the optimum conditions which should also be at hand, making the use of photovoltaics as the power source for pumping water one of the most promising areas of PV application. Photovoltaic powered water pumping systems need adequate sunshine and a source of water. The use of photovoltaic power for water pumping becomes especially appropriate, as there is often a normal relationship between the presence of solar power and the water requirement. The requirement increases during hot weather when the solar radiation intensity is high and the output of the solar array is at its maximum. On the other hand, the water requirement decreases when the weather is cool and the sunlight is less intense. What makes the study relevant for this context is the similar conditions which were present, underlining the suitability of the water pumps powered by photovoltaics for water supply in remote areas where no electricity is otherwise available. Water can be pumped during the day and stored in tanks and it will be available at night or when no sunlight is available, for example when it is cloudy. The pumped water can also be used in other purposes such as domestic use which is one of the purposes suggested in the current paper as well. The advantages of using water pumps powered by photovoltaics are the following low maintenance, easy installation, reliability and a matching between the power generated and the water usage which is needed. Also, water tanks can be used instead of batteries in photovoltaic pumping systems.

One significant reason why innovation is needed and will prove very useful for all aspects of life in the agricultural context is the growing demand for agricultural production worldwide. Therefore, regardless of the region or the specific conditions, this fact is a growing problem in all parts of the world, making the discussion of this paper an important one not only for the specific case study discussed. The same argument is argued by Jones M.A. et all in the paper "Economic 
analysis of photovoltaic (PV) powered water pumping and desalination without energy storage for agriculture", where it was a result of the increasing pressure due to population growth.

Another study, conducted by Aguilar et. al. in 2019 approaches the subject from a technoeconomic perspective The authors have evaluated the feasibility from economic standpoint and the environmental benefits of a photovoltaic assisted heat pump water heater. The paper is based on experimental data collected over one year for a family of four members and their domestic hot water consumption. The analysis considers the lifetime cost of the heating system and the environmental benefits of using it compared to conventional ones, such as a heat pump not powered by photovoltaic energy, an electrical heater and a boiler. The conclusions reached were that the non-renewable energy use was reduced almost $80 \%$ and the emissions were also reduced by approximately $80 \%$ in comparison to the use of a boiler. From the results of the research it was concluded that the use of photovoltaic panels is also the cheapest option, but the evaluation of the profitability is highly dependent on the energy prices.

Additionally the performance of photovoltaic water pumping systems was also investigated during an experiment of panel cooling using air and water. The experiment was conducted in India during 2017 and was performed using four different cooling methods. According to Mohanraj M. et al. (2019), the research confirmed that using photovoltaic powered water pumping assisted by a cooling method it is possible to reduce the carbon-dioxide emissions by approximately 20.4 tons during twenty years lifetime of the panels in comparison to water pumping systems powered by coal based power plants.

Therefore, the photovoltaic powered water pumps may represent an eligible solution and have the potential to facilitate water supply.

The context in which the need for alternative energy resources has become urgent is the one of the transition to green energy and in order to measure the socio-economic impact, the European House Ambrosetti has proposed an innovative model of assessment for the impact on three countries within the European Union: Italy, Spain and Romania.

In the timeframe considered (reference time being 2030), the production outcome of the transition and its influence on employment were analyzed by combining micro and macro approaches and referencing a number of 3,745 products and technologies within the respective countries through literature reviews, desk analysis and expert panels. Among the three countries, Romania was of interest through the share of renewable energy above the European average, but with a GDP per capita below average. Also, thermal technologies represent an important share in the manufacturing sector.

\section{Methodology}

The hypothesis of the paper is that the use of solar powered water pumps in agriculture is a viable solution for economic development in line with the goals set by the European Union for the energy transition process. The purpose is to assess the impact of the above mentioned solution.

The methodology guideline is the one proposed by the European House Ambrosetti which will be applied to the context approached in the paper, and it consists of mapping all products and technologies required for the transition or affected by it, followed by a map of value chains involved in different steps of the process: Research and Development (competences and skills needed in different technologies), Manufacturing (of different parts for constructing components required) and Distribution sales and aftermarket which also imply Recycling and second life of the used products. 
It was concluded that the digital services will have the most significant impact and the value added by these services was estimated to approximately one billion EUR in Romania through the services it will create. Furthermore, the effect on the industrial sector was assessed by dividing relevant clusters according to the NACE code of the activities and assessing them for each country considered.

In Romania, electric technologies (such as solar panels, heat pumps, LED lamps, etc.) will amount to 8-10 billion EUR, and the use of thermal technologies (boilers or internal combustion engines) will increase with about one billion EUR, whereas neutral technologies (ex. car glass or pneumatic tires - representing auxiliary products) will increase anywhere between 3 and $26 \%$. The final net impact of the energy transition at the reference date 2030 on the industrial (production) sector for Romania was estimates to be a growth ranging between 2 and 3\% in production value.

The effect on employment in Romania was assessed to be a 30\% growth of employees in electric technologies compared to 2017 with a decrease of $11 \%$ of the employees in the thermal sector. The number of employees in the neutral sector is also expected to rise with about $28 \%$.

To these aspects, an increase in the level of employment will also result in the digital sector, as the innovation will be mainly originating thereof. But the added value created must be supported by significant investments in the development of power generation and distribution, as well as the end-use sector, in order for them to be viable for the energy transition. According to the report, a cumulated investment of about 2.3 trillion EUR until 2028 is estimated at the level of the European Union, with about 5 billion being required for investment in Romania.

The next effect evaluated is the one on air quality, which is one of the main concerns for the European Union, where the transportation sector accounts for the majority of the emissions generated. As a solution, the pollutants generated will be significantly reduced by the substitutions of the older vehicles with electric ones until 2030.

The study also refers to the impact on human health and cost savings. The air pollution being a major cause for diseases which cause about 400 thousand premature deaths, the above mentioned measures would decrease this number by approximately 5000 at the level of EU.

The related costs per ton of emission would also be reduced by an estimated amount between 1 and 3 billion euros.

In conclusion, the four important areas to approach in order to identify the total impact are:

1. Economic effects

2. Social effects

3. Employment

4. Air quality

\section{Results and discussions}

According to Loizou E., Karelakis C., Galanopoulos K. \& Mattas K. (2019), the economic sectors related to people's basic needs, like agriculture, present economic resistance in times of turbulence (such as the economic crisis from 2008). Therefore they represent a source of stability, promoting continuous economic growth and sustaining the employment level.

Moreover, in the study above mentioned it was concluded that agriculture has the potential of driving other sectors towards their development and it can promote the integrated economic progress of the region.

Considering these aspects, it can be considered that the agricultural sector may be an important element of the national economy of Romania. Further in this paper it can be concluded why it is considered to have significant importance but also some significant deficiencies. 
Over the last 10 years, the contribution of agriculture to the total GDP in Romania represented more than $5 \%$, thus indicating the importance of this sector.

In order to understand the priorities regarding the development of this sector, the latest report of the Agriculture and Rural Development Ministry can be referenced, where one of the main concerns is represented by the reconditioning and extension of the irrigation system. With this purpose, a rehabilitation program financed exclusively from State budget sources will carry out works to rehabilitate the main phased irrigation infrastructure which has the aim to rehabilitate the main irrigation infrastructure which supplies pressure stations until this year (2020). The main irrigation infrastructure consists of plugs, base pumping stations (fixed or floating) including reversible ones, pump stations, their associated electrical grid, collectors, pipelines, and pipes for irrigation water supply and distribution to pressure pumping stations. (Government Decision no. 793/2016).

Romanian irrigation systems were built up until 1990, when the irrigated area occupied about $22 \%$ of the country's agricultural area and about $34 \%$ of the arable area. Romania currently has an area of some 3.1 million ha of agricultural land to be considered. Of this area, 1,5 million ha is the viable and marginal viable area out of which the irrigated area is currently approx. 823.000 ha. The actual irrigated area varies widely from year to year depending on precipitation. It is estimated that approximately $11 \%$ of the country's agricultural area is covered by economically viable or marginal irrigation networks. There are also regional differences, especially as a reflection of varying rainfall patterns and irrigation needs. The North-West, West and Center regions need less irrigation water, while South and South-East areas, where drought is a known issue, enjoy greater coverage with irrigation systems.

The main problems related to the irrigation systems, according to the Ministry of Agriculture and Rural Development, are: low hydraulic efficiency; increased electricity costs for pumping-based systems (the Danube being the main water source); increased cost of water supply.

Irrigation facilities are in an advanced stage of degradation and for $75 \%$ of the surface area of these facilities, irrigation is not functional, whereas functional ones are inefficient in water and energy use and costly for farmers. The existing irrigation infrastructure in Romania is exceeded in terms of resource efficiency and there is a risk that abandoning irrigation infrastructure will generate serious social, economic and environmental problems.

Aside from the analysis of the government's program for the purpose of rehabilitating the irrigation system, the lack of stability of the agricultural system can be observed in the figure below, which represents the evolution of crops between 2000 and 2018. Significant variations can be observed, indicating a strong link to the weather conditions from one year to another. 


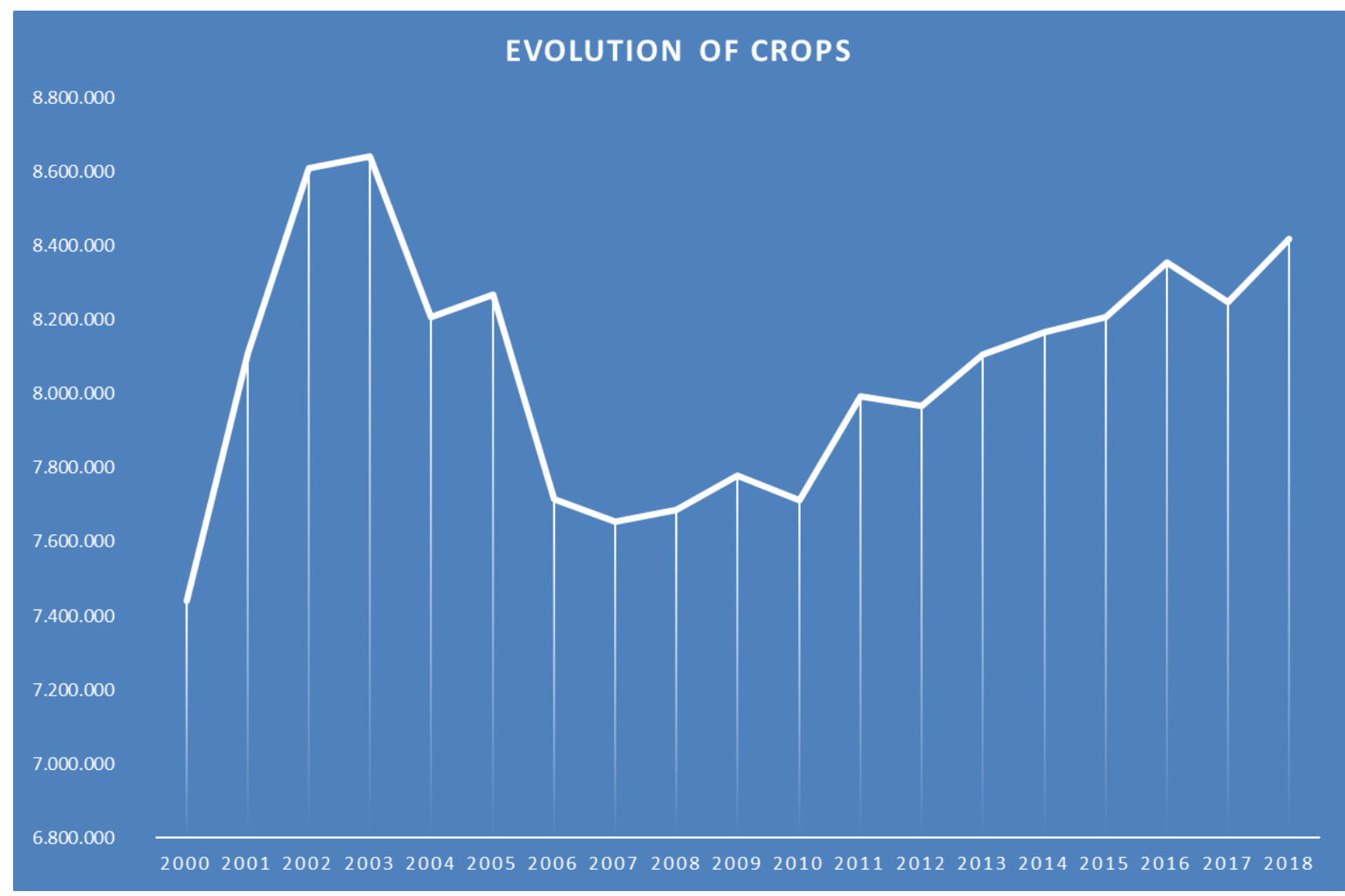

PICBE $\mid 79$

\section{Figure 1. Evolution of crops in Romania 2000-2018}

Source of data: http://www.insse.ro/cms/ro/

Furthermore, the link between the evolution of agricultural generated income in Romania and the total GDP can also be observed in the figure below, as the trend of the two has consistently been the same for the last 19 years (2000-2019). Therefore, it can be assumed that the trends and performance of the agricultural sector have a significant influence on the general economy of the country.

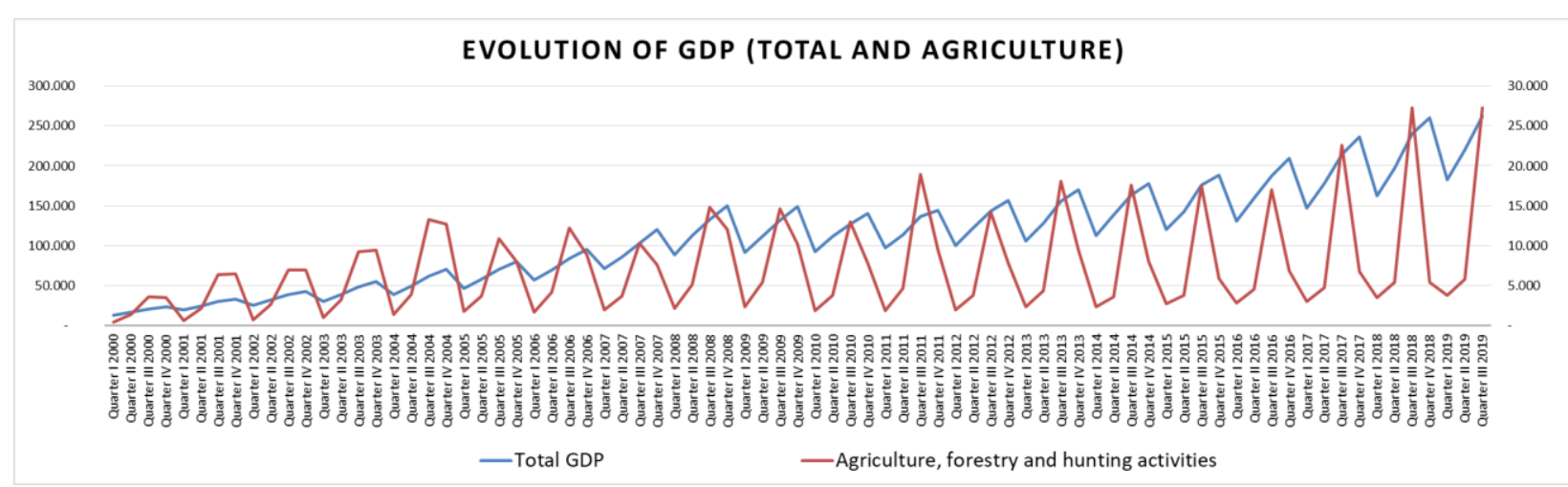

Figure 2. Evolution of GDP (Total and Agriculture) 2000-2019

Source of data: http://www.insse.ro/cms/ro/.

Out of total 1.5 million ha, 700.000 ha is unirrigated viable agricultural land, according to the latest decision of the Government regarding the ongoing national infrastructure rehabilitation 
program. This represents an area of great potential from both economic and social perspective, which could be exploited in a way that is also in line with the requirements of the EU regarding the transition to green energy. Therefore, a viable solution can be the utilization of water pumps powered by photovoltaic energy in order to irrigate the agricultural land above mentioned so that the production will not depend strictly on the weather conditions.

Following the assessment model proposed by the Ambrosetti House, the following effects

PICBE | 80 can be estimated:

1. Economic effects:

According to Romstal, which is a company specialized in the sale of plumbing used in construction, a photovoltaic powered water pump can extract about 5.5 cubic meters of water per hour. This represents 5.500 liters per hour of extracted water. A water pump powered by solar panels can have an average of six hours working time per day, in accordance with the average daily sun radiation estimated in the professional manual for solar energy powered systems. This results in a potential of 33.000 liters of water extracted daily.

For an average demand of 5.5 liters/square meter/day of water for an agricultural crop, it means that one solar powered water pump will serve 0,6 hectares of agricultural land (33.000 liters for a demanded 5.5 liters/ square meter $=6.000$ square meters).

As a result, for the total 700.000 hectares of agricultural land, approximately 117.000 water pumps would be required for irrigation purposes (700.000/0.6).

With an estimated cost of 5.000 EUR per water pump, the total turnover generated would be $5.000 \times 117.000=585$ Mil. EUR.

Additionally, the GDP generated by agriculture will automatically increase, estimating it will be doubled as the abovementioned agricultural land plots represent almost half of the viable land.

2. Social effects:

In Romania there are a number of approximately two million homes without access to running water, comprising almost $30 \%$ of the total population of Romania. This has a significant impact on the quality of life for the individuals, and in 2018 the World Bank has issued a report, where it refers to this issue and moreover, it is stated that the European Union legislation has not addressed the need for universal access to water supply. The deficit of access in Romania affects approximately 4.5 Mil people, which represents a threat for their health as well, due to the improper sources they rely on (which are close to the surface and are subject to contamination).

Moreover, this issue persists in the rural areas, therefore a water pump used for the irrigation of agricultural land can also serve in majority of cases also as a solution for the individuals living in the area. This would significantly contribute to the increase of the quality of life of the families and the cost would be marginal, as the average water consumption is at most about 137 liters/day (this being the average daily consumption in Bucharest according to the company which supplies water - Apa Nova). This consumption is an almost unnoticeable fraction of the daily extraction capacity of the pump.

Therefore, the social effect is potentially a very consistent for the development of the country as a whole, and it surpasses the ecological dimension of the solution.

\section{Air Quality:}

According to the US Energy Information Administration, the use of solar panels does not produce air pollution. As a result, the use of photovoltaic powered water pumps is in line with the 
goal for energy transition, which must be a fair one for all individuals, by encouraging economic and social development and at the same time fulfilling ecological restrictions for the purpose of building a sustainable future.

However, although the air quality is not affected during the use, there are some aspects which need to be considered.

Firstly, the panels are composed by some toxic materials and chemicals and they also use hazardous fluids in order to transfer the heat captured from the sun. Therefore, the disposal of the panels after their lifetime needs to be done in a controlled manner according to the applicable regulation.

Secondly, the panels may also affect the environment in which they are installed, namely the ecosystem for example by killing the birds and insects which fly into the beam of concentrated sunlight.

As a result, it is mandatory to dispose safely of the panels after use and therefore, qualified personnel is required in order to avoid accidents.

\section{Employment:}

As mentioned above, the disposal of de panels requires authorized personnel. The same applies for the installation of the water pumps.

The date set by the European Union for the completion of the energy related goals is 2030 and for reference, if there are in average 250 working days in one year and the estimated installation time for the submersible water pump is 2 days, then it can be assumed that minimum 100 employees (117.000 water pumps * 2 days for installation / 251 working days / 10 years until 2030) are required just for the installation of the pumps. Subsequently, the disposal will also require trained individuals, as well as the maintenance of the systems and the auxiliary activity. Therefore it is reasonable to assume that minimum 200 jobs will be created throughout the country for this purpose.

\section{Conclusion}

In conclusion, the use of photovoltaic powered water pumps is indeed a viable solution suitable in the context of the energy transition which accounts both for economic and social development and therefore the research hypothesis was validated. Given the dimensions to be considered and the fact that it represents a significant investment opportunity, it is necessary for the policymakers (both local as well as at the level of the EU) to be involved in the implementation.

\section{Limits of the research}

The paper discusses the potential of using photovoltaic water pumps to insure the necessary quantity of water in order to facilitate the irrigation of agricultural land. However, additional infrastructure and pipelines need to be installed in order for this potential solution to become viable. This is not possible without intervention of the authorities and inclusion of the initiative in a plan at national level.

\section{References}


Aguilar F., Crespí-Llorens D. \& Quiles P.V. (2019). Environmental benefits and economic feasibility of a photovoltaic assisted heat pump water heater. Solar Energy, 193, 20-30.

Fu H., Li G. \& Li F. (2019). Performance comparison of photovoltaic/thermal solar water heating systems with direct-coupled photovoltaic pump, traditional pump and natural circulation. Renewable Energy, 136, 463-472.

Ghoneim, A.A., (2016). Design optimization of photovoltaic powered water pumping systems. Energy Conversion and Management, 47(11-12), 1449-1463.

Government Decision no. 793/2016. Retrieved from: https://sgg.gov.ro/new/wpcontent/uploads/2018/07/HG-54.pdf

Jones, M. A., Odeh, I., Haddad, M., Mohammad, A. H., \& Quinn, J. C. (2016). Economic analysis of photovoltaic (PV) powered water pumping and desalination without energy storage for agriculture. Desalination, 387, 35-45.

Loizou E., Karelakis C., Galanopoulos K. \& Mattas K. (2019). The role of agriculture as a development tool for a regional economy. Agricultural Systems, 173, 482-490.

Mohanraj M., Chandramohan P., Sakthivel M. \& Sopian K. (2019). Performance of photovoltaic water pumping systems under the influence of panel cooling. Renewable Energy Focus, 31 , 31-44.

The European Commission. Solar Thermal applications in EASTern Europe with Guaranteed Solar Results. Retrieved from: https://ec.europa.eu/energy/intelligent/projects/sites/ieeprojects/files/projects/documents/east-gsr_training_manual_romania.pdf

The European House Ambrosetti (2019). The socio-economic impacts of energy transition in Europe. Retrieved from https://www.ambrosetti.eu/en/research-and-presentations/just-evolution-2030-the-socio-economic-impacts-of-energy-transition-in-europe/

The World Bank (2018). Diagnostic report over the waters of Romania. Retrieved from: http://documents.worldbank.org/curated/en/618431556178394272/pdf/Raport-DiagnosticPrivind-Apele-din-Rom\%C3\%A2nia-Rezumat-Executiv.pdf

US Energy Information Administration (2019). Solar energy and the environment. Retrieved from: https://www.eia.gov/energyexplained/solar/solar-energy-and-the-environment.php 